\title{
NALLD Market
}

The NALLD Market provides a service for lab directors and schools faced with the problem of disposing of master tapes for texts no longer used and equipment no longer needed. The NALLD Journal will list such tapes and equipment for sale by schools. Only tapes sold by the publisher to the school and still in the original package will be listed.

Please note that NALLD and the NALLD Journal accept no responsibility for the transportation of items between buyer and seller. The quality of the materials and the method of payment for them should be a matter established between the buyer and seller before the transaction is made.

The listings in the Journal will be determined by the space available. The NALLD Journal reserves the right to select listings.

Information for tapes offered for sale should be presented in the following form in the order indicated:

Language, title, author, editor, publisher, year, number of reels, number of tracks, recording speed, original cost, selling price (we suggest 50 percent discount), person to contact.

Equipment for sale should be listed as follows in the order indicated:

Type of equipment, manufacturer, description of pertinent features as applicable (as briefly and concisely as possible), condition, year of purchase, original cost, selling price, person to contact.

Listings for the NALLD Market should be sent to C. P. Richardson, Editor, NALLD Journal, Ellis Hall 26-A, Ohio University, Athens, Ohio 45701.

\section{TAPES}

\section{GERMAN}

GERMAN REVIEW AND PRACTICE - Goedsche and Spann, Van Nostrand Reinhold Co. Complete set of nine tapes, new. Selling price: $\$ 15$

CONTACT: Dr. Leonhard E. Baak, Chairman, Department of Modern Languages, Morningside College, Sioux City; Iowa 51106. 
NALLD Market

SPANISH

BEGINNING SPANISH - DaSilva, Harper and Row, 2nd Ed., 3 3/4 ips, 42 reels including tests and repases, full track, selling price, $\$ 75$. CONTACT: Carroll E. Naves, Language Laboratory Director, Barry College, Miami, Florida 33161.

EQUTPMENT

LISTENING LABORATORY: Monaural Webster listening laboratory system including eight Ekotape decks, two Bogen turntables, seven amplifiers and seven headphones; seven years old. Price negotiable.

CONTACT: Dr. Lawrence DeWitt, Chairman, Department of Music, Morningside College, Sioux City, Iowa 51106. 